DOI:10.15171/ipp.2019.16

\title{
Lung cancer risk and the inhibitors of angiotensin- converting enzyme: A mini-review of recent evidence
}

\author{
Masoumeh Asgharpour $^{1 \oplus}$, Mohammad Ebrahimi Kalan ${ }^{2}{ }^{\circledR}$, Seyed Hadi Mirhashemi ${ }^{3}$, Amirhesam Alirezaei ${ }^{4 *(\mathbb{}}$ \\ 'Department of Nephrology, Rouhani Hospital, Babol University of Medical Sciences, Babol, Iran \\ ${ }^{2}$ Department of Epidemiology, Robert Stempel College of Public Health, Florida International University, Miami, FL, USA \\ ${ }^{3}$ Department of Surgery, Loghman hakim Hospital, Shahid Beheshti University of Medical Sciences, Tehran, Iran \\ ${ }^{4}$ Urology and Nephrology Research Center, Shahid Modarres Hospital, Shahid Beheshti University of Medical Sciences, \\ Tehran, Iran
}

*Correspondence to

Amirhesam Alirezaei, Email: amirhesam124@gmail.com and

Aalirezaei@sbmu.ac.ir

Received 10 April 2019 Accepted 20 June 2019

Published online 14 July 2019

Keywords: Cancer, Reninangiotensin system inhibitors, Antihypertensive medications, Renin-angiotensin system

Citation: Asgharpour M, Ebrahimi Kalan M, Mirhashemi SH, Alirezaei A. Lung cancer risk and the inhibitors of angiotensinconverting enzyme: A minireview of recent evidence. Immunopathol Persa. 2019;5(2):e16. DOI:10.15171/ ipp.2019.16

\section{Abstract}

Angiotensin-converting enzyme inhibitors (ACEIs) are among the most widely prescribed antihypertensive medications. They are indicated in the management of multiple chronic conditions including hypertension, diabetes mellitus and heart failure. ACEls prevent angiotensin II (Ang II) production and bradykinin catabolism leading to vasodilation and reduction of arterial blood pressure. Recently, the role of the reninangiotensin system (RAS) inhibitors has become the subject of scrutiny in the treatment of cancer metastasis. The administration of ACEls, however, has been described to be accompanying with carcinogenic effects.

\section{Introduction}

The angiotensin-converting enzymes (ACEs) are active components in reninangiotensin-aldosterone system (Figure 1). Renin-angiotensin-aldosterone system plays a major role in the regulation of extracellular volume and arterial vasoconstriction. ACE is mainly produced in the lungs by pulmonary endothelial cells and converts the angiotensin I hormone to the active vasoconstrictor, angiotensin II (1). Along with calcium antagonists (32.2\%), ACEIs are among the most widely prescribed (41\%) antihypertensive medications (2). ACEIs are widely available and can be administered in compound with other anti-hypertensive drugs (3).

Although short-term administration of ACEIs seems to be safe, their long-term consumption may induce adverse effects such as dry cough, hyperkalaemia and orthostatic hypotension. Furthermore, some recent studies have declared that ACEIs may enhance the risk of cancer. For example, in a cohort study on 992061 patients, treatment with ACEIs was shown to be associated with an increased risk of lung cancer (4). In fact, lung cancer still is the most common

\section{Key point}

Angiotensin-converting enzyme inhibitors prevent the separation of bradykinin and therefore strengthen the circulating levels of bradykinin which may participate in tumorigenesis.

neoplasm worldwide with more than 2 million incidences in 2018 alone (11.6\% of all cases) (5).

Despite findings from observational studies, the carcinogenic effect of ACEIs have not been yet adequately addressed in the literature. It must be pointed out, however, the controversies between results of various studies may be due to different clinical conditions or co-prescribed medications.

In addition to activating angiotensin I, ACE also metabolizes bradykinin, a circulating peptide released from the cleavage of highmolecular-weight kininogen (HMWK) (6). Along with histamine, bradykinin also has a role as a vasoactive substance in inflammatory processes. Bradykinin plays a vital role in the pathophysiology of inherited C1-esterase inhibitor deficiency. The administration of ACEIs may increase the level of bradykinin in the lungs which

\footnotetext{
Copyright (C) 2019 The Author(s); Published by Nickan Research Institute. This is an open-access article distributed under the terms of the Creative Commons Attribution License (http://creativecommons.org/licenses/by/4.0), which permits unrestricted use, distribution, and reproduction in any medium, provided the original work is properly cited.
} 


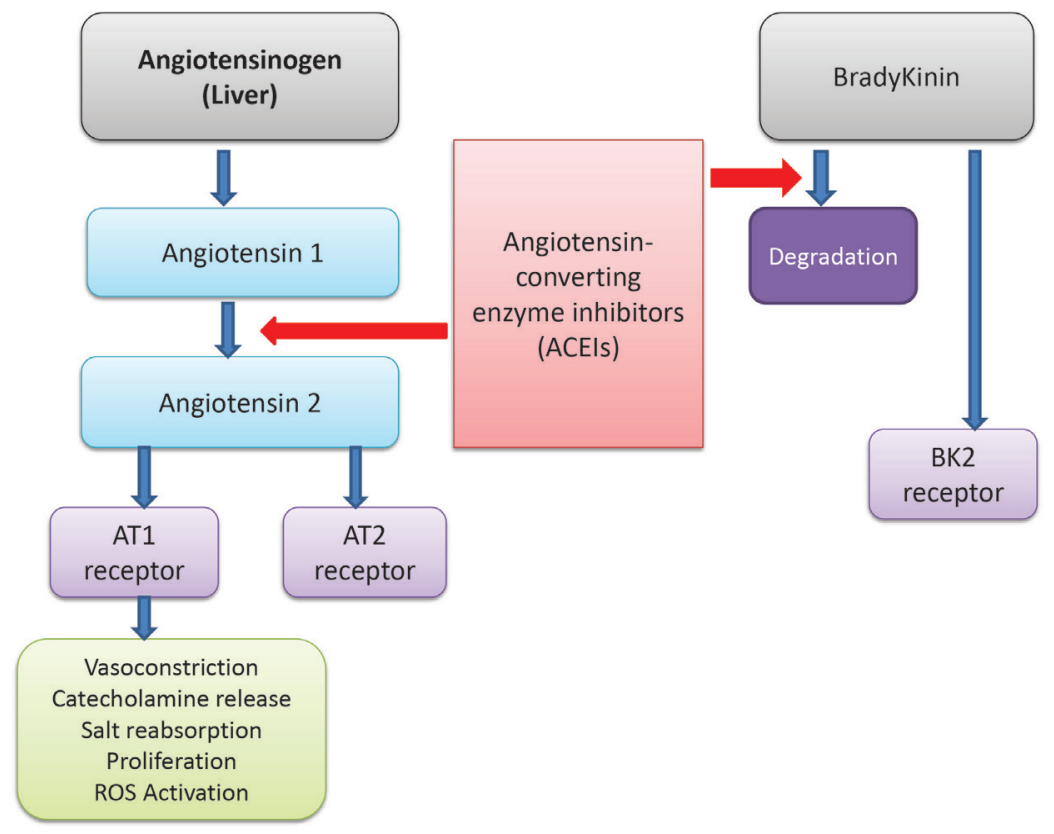

Figure 1. The overview of the renin-angiotensin system and angiotensin II receptors.

subsequently can stimulate the growth of lung cancer cells (4). Bradykinin has also been reported to induce the release of vascular endothelial growth factor (VEGF) which promotes angiogenesis (7). Moreover, bradykinin can augment the lung cancer progression by regulating blood vessel permeability and promoting tumour invasion and metastasis (8). Additionally, the administration of ACEIs has been associated with tumour proliferation and angiogenesis through overproduction of substance $\mathrm{P}$ which is expressed in lung cancer tissues (9). Finally, a well-documented common side-effect of ACEIs is dry and persistent coughing that is supposed to be the result of ACEIs impacts on the metabolism of bradykinin and substance P (10). However, a recent study showed no significant differences in the levels of bradykinin and substance $\mathrm{P}$ in the lungs before and after administration of ACEIs and angiotensin receptor blockers (11). Accordingly, the aim of this review was to discuss the current evidences regarding the limitations and outcomes of ACEIs in the treatment of hypertension.

\section{Materials and Methods}

For this mini-review, we used a variety of sources including PubMed, Web of Science, Embase, EBSCO, Google Scholar and Scopus. The search was conducted by using combinations of the following key words and or their equivalents; antihypertensive medications, cancer, renin-angiotensin system inhibitors, renin-angiotensin system and lung cancer.

\section{Mechanism of action}

The process of ACEIs action is interrelated with the renin-angiotensin-aldosterone system. ACEIs hinder the production of Ang II. Ang II mediates its actions through both type 1 (i.e. AT1) including vasoconstriction, cell growth, aldosterone release, renal sodium resorption and sympathetic activation and type 2 (i.e. AT2) mediates vasodilation, and inhibition of cell growth (Figure 1).

The major limitation of ACEIs is the failure to effectively prevent Ang II production probably due to persistent low-level production of this vasoactive agent through ACE-independent pathways. Through the activation of AT2 receptors, Ang II may promote vasodilatory and anti-proliferative activities. In fact, ACEIs prevent the separation of bradykinin and therefore strengthen the circulating levels of bradykinin which may participate in tumorigenesis (12). Bradykinin has also been reported to play a significant role in mediating vasodilation (13). Moreover, bradykinin increases the synthesis of potent vasoactive agents such as nitric oxide and prostaglandins (14). Through these effects, ACEIs are believed to play a major role in cancer development (15).

\section{Comparison of outcomes}

Individuals without cardiac insufficiency

In individuals with high blood pressure, treatment with ACEIs has significantly reduced all-cause mortality (16). Because of the high prevalence of hypertension, using ACEIs to manage this condition may save many lives (16). In a large meta-analysis of randomized placebocontrolled trials, on patients with hypertension and no heart failure, it was indicated that the efficiency and safety of ARBs (angiotensin-receptor blockers) and ACEIs were comparable (17).

Likewise, in a meta-analysis on patients with high risk 
of cardiovascular disease (CVD) (without heart failure), the mortality rate was compared between individuals treated with either ARBs or ACEIs (18). The study showed no substantial evidence on the superior impact of ACEIs in preventing CVD related mortality in comparison to ARBs. Therefore, evidence indicates similar efficacy of ARBs and ACEIs in preventing mortality in patients with hypertension and high risk of $\mathrm{CV}$ events.

\section{Patients with coronary artery disease}

The efficiency of ACEIs in patients with coronary artery disease is yet to be verified in future researches (19). Only indirect comparisons have been conducted on the core of the myocardial infarction paradox. Although it has been proposed that ARBs may be safer than ACEIs, this theory suffers from the lack of data from direct head-to-head trials (20).

\section{Patients with heart failure}

ACEIs have been confronted with placebo in numerous clinical trials on individuals with heart failure (2). A meta-analysis by Burnett et al demonstrated that ACEIs administration in individuals with chronic heart failure reduced the mortality rate compared to placebo (21).

Furthermore, the "Cooperative North Scandinavian Enalapril Survival" study reported $31 \%$ decrease in 1 -year mortality rate in individuals with serious cardiac insufficiency remedied with ACEIs when compared to placebo (22). Packer et al (23) have detected the efficacy of ACEIs to their impacts on endogenous compensatory vasoactive substances that are recruited by ACEIs but not by ARBs. This fact may pave the route for wider application of the RAS inhibitors as potential endogenous vasoactive peptides in patients with heart failure.

\section{Patients with chronic kidney disease}

In a multi-center, randomized, double-blind, controlled clinical trial on 25620 participants at high risk of vascular events, ACEIs showed similar effects compared with ARBs in terms of primary renal outcomes including dialysis, doubling of serum creatinine and mortality (24).

\section{Diabetic patients}

Barnett et al, conducted a double-blind, randomized clinical trial, multicenter study on 250 subjects with type 2 diabetes. They found, the effects of ACEIs on the secondary outcomes were not significant following five years of treatment (25). Accordingly, in a meta-analysis of 71 clinical trials on diabetic patients, no notable difference was detected in the all-cause mortality rate between the users of either ACEIs or ARBs (26).

\section{Patients with cerebrovascular disease}

Most head-to-head analysis revealed no variation in the stroke rates comparing patients with cerebrovascular disease treated with either ARBs or ACEIs (27). In a recent meta-analysis on patients with systolic hypertension, ACEIs reduced cardiovascular outcomes compared with placebo; nevertheless, they were unsuccessful to inhibit stroke (28).

\section{Adverse events}

ACEIs have been associated with dry and irritating coughing as their most common adverse effect (29). This event has encouraged many physicians to no longer prescribe ACEIs. In addition, Banerji et al (30) reported that among 134,945 patients administrated with ACEIs, $0.7 \% \quad(n=888)$ developed angioedema following five years. Compared with ARBs, Hicks et al in a populationbased cohort study revealed an increased risk of lung cancer associated with ACEIs with the highest risk being observed at more than ten years after ACEIs utilization (4). In the recent study, authors reported that ACEIs were accompanied with $14 \%$ greater overall risk of lung cancer (hazard ratio $=1.14,95 \%$ confidence interval; 1.01 to 1.29 ) (4). Although the $14 \%$ increase in the risk of lung cancer may not turn to a large uncontrolled risk, the findings are significant given the substantial usage of ACEIs worldwide.

\section{Anti-cancer impact of ACEIs}

By the way, recent evidence has detected the role of reninangiotensin system (RAS) in tumoral alteration and its progression (31). Consequently, the probable anti-cancer mechanisms of RAS blockers consist of modulating nuclear factor (NF)- $\mathrm{kB}$, prevent matrix metalloproteinases (MMP-9 and MMP-2) production, a suppressing effect on VEGF, and diminish the production of hypoxia-inducible factor 1 (HIF-1). Accordingly, probable anti-cancer mechanisms of RAS blockers may be due to stimulation of angiostatin (only captopril), and diminish the aggregation of tumour-related macrophages by MCP-1 decrement, finally directing to reduced micro-vessel compactness and lessening of the tumour inflammatory location, and also tumour development reversion. These important findings should keep in mind when we talk about the impact of ACEIs on lung cancer (31-34). In fact, the study by Hicks et al (4), needs further investigation by more multi-centric, multi-ethnic studies.

\section{Conclusion}

The clinical efficiency of ACEIs is a controversial topic in the scientific community with some studies have suggested increased, decreased, or unchanged risk of cancer in patients treated with ACEIs (32-35). Meta-analyses which are based on registered data of big populations may be beneficial to extrapolate long-term effects of ACEIs; however, these may not be indicated to predict outcomes in small clinical trials. Nevertheless, in an individual patient, concerns about the long-term risk of lung cancer should be balanced against gains in life expectancy associated with the administration of ACEIs. Further comprehensive studies are needed to provide more valid scientific evidence 
on the long-term safety of ACEIs.

Authors' contribution

MA, SHM and AHA participated in the conception of the study, data collection and analysis, and drafted the manuscript. MA, MEK, SHM and AHA contributed to drafting, critical reviewing, and finalization of the manuscript. All authors contributed to development of the manuscript and approved the final manuscript.

Conflicts of interest

The authors declared no competing interests.

Ethical considerations

Ethical issues including plagiarism, double publication, and redundancy have been completely observed by the authors.

\section{Funding/Support}

None.

\section{References}

1. Talambedu Usha PT, Veena Pande, Sushil Kumar Middha. Molecular Docking and Quantum Mechanical Studies on Pelargonidin-3-Glucoside as Renoprotective ACE Inhibitor. ISRNComputational Biology. 2013. doi:10.1155/2013/428378.

2. Marquez PHP, Torres $\mathrm{OH}$, San-Jose A, Vidal $\mathrm{X}$, Agusti A, Formiga $\mathrm{F}$, et al. Potentially Inappropriate Antihypertensive Prescriptions to Elderly Patients: Results of a Prospective, Observational Study. Drugs Aging. 2017;34:453-66. doi: 10.1007/s40266-017-0452-z.

3. Messerli FH, Bangalore S, Bavishi C, Rimoldi SF. AngiotensinConverting Enzyme Inhibitors in Hypertension: To Use or Not to Use? J Am Coll Cardiol. 2018;71:1474-82. doi: 10.1016/j. jacc.2018.01.058.

4. Hicks BM, Filion KB, Yin H, Sakr L, Udell JA, Azoulay L. Angiotensin converting enzyme inhibitors and risk of lung cancer: population based cohort study. BMJ. 2018;363:k4209. doi: 10.1136/bmj.k4209.

5. Bray F, Ferlay J, Soerjomataram I, Siegel RL, Torre LA, Jemal A. Global cancer statistics 2018: GLOBOCAN estimates of incidence and mortality worldwide for 36 cancers in 185 countries. CA Cancer J Clin. 2018;68:394-424. doi: 10.3322/ caac. 21492

6. Simões e Silva AC, Teixeira MM. ACE inhibition, ACE2 and angiotensin-(1-7) axis in kidney and cardiac inflammation and fibrosis. Pharmacol Res. 2016;107:154-162. doi: 10.1016/j. phrs.2016.03.018.

7. Sethi T, Rozengurt E. Multiple neuropeptides stimulate clonal growth of small cell lung cancer: effects of bradykinin, vasopressin, cholecystokinin, galanin, and neurotensin. Cancer Res. 1991;51:3621-3.

8. Trifilieff A, Da Silva A, Gies JP. Kinins and respiratory tract diseases. Eur Respir J. 1993;6:576-87.

9. Munoz M, Covenas R. Involvement of substance P and the NK-1 receptor in human pathology. Amino Acids. 2014;46:1727-50. doi: 10.1007/s00726-014-1736-9.

10. Vegter S, de Jong-van den Berg LT. Misdiagnosis and mistreatment of a common side-effect-angiotensin-converting enzyme inhibitor-induced cough. $\mathrm{Br} J$ Clin Pharmacol. 2010;69:200-3. doi: 10.1111/j.1365-2125.2009.03571.x.

11. Gokhale M, Girman C, Chen Y, Pate V, Funk MJ, Sturmer T. Comparison of diagnostic evaluations for cough among initiators of angiotensin converting enzyme inhibitors and angiotensin receptor blockers. Pharmacoepidemiol Drug Saf. 2016;25:512-20. doi: 10.1002/pds.3977.

12. Hanif K, Bid HK, Konwar R. Reinventing the ACE inhibitors: some old and new implications of ACE inhibition. Hypertens Res. 2010;33:11-21. doi: 10.1038/hr.2009.184.

13. Pelc LR, Gross GJ, Warltier DC. Mechanism of coronary vasodilation produced by bradykinin. Circulation. 1991;83:2048-56.

14. Abdi R, Dong VM, Lee CJ, Ntoso KA.Angiotensin II receptor blocker-associated angioedema: on the heels of ACE inhibitor angioedema. Pharmacotherapy. 2002;22:1173-5.

15. Clere N, Corre I, Faure S, Guihot AL, Vessieres E, Chalopin M, et al. Deficiency or blockade of angiotensin II type 2 receptor delays tumorigenesis by inhibiting malignant cell proliferation and angiogenesis. Int J Cancer. 2010;127:2279-91.

16. van Vark LC, Bertrand M, Akkerhuis KM, Brugts JJ, Fox K, Mourad JJ,et al. Angiotensin-converting enzyme inhibitors reduce mortality in hypertension: a meta-analysis of randomized clinical trials of renin-angiotensin-aldosterone system inhibitors involving 158998 patients. Eur Heart J. 2012;33:2088-97. doi: 10.1093/eurheartj/ehs075.

17. Li EC, Heran BS, Wright JM. Angiotensin converting enzyme (ACE) inhibitors versus angiotensin receptor blockers for primary hypertension. Cochrane Database Syst Rev. 2014. doi: 10.1002/14651858.CD009096.pub2.

18. Schmieder RE, Hilgers KF, Schlaich MP, Schmidt BMW Renin-angiotensin system and cardiovascular risk. Lancet. 2007;369:1208-19. DOI:10.1016/S0140-6736(07)60242-6.

19. Nissen SE, Tuzcu EM, Libby P, Thompson PD, Ghali M, Garza $D$, et al. Effect of antihypertensive agents on cardiovascular events in patients with coronary disease and normal blood pressure: the CAMELOT study: a randomized controlled trial. JAMA. 2004;292:2217-25. DOI:10.1001/jama.292.18.2217.

20. Messerli FH, Bangalore S. Angiotensin Receptor Blockers Reduce Cardiovascular Events, Including the Risk of Myocardial Infarction. Circulation. 2017;135:2085-7. doi: 10.1161/CIRCULATIONAHA.116.025950.

21. Burnett H, Earley A, Voors AA, Senni M, McMurray JJ, Deschaseaux $C$, et al. Thirty years of evidence on the efficacy of drug treatments for chronic heart failure with reduced ejection fraction: a network meta-analysis. Circ Heart Fail. 2017;10: e003529. doi: 10.1161/CIRCHEARTFAILURE.116.003529.

22. Swedberg K, Held P, Kjekshus J, Rasmussen K, Rydén L, Wedel $H$. Effects of the early administration of enalapril on mortality in patients with acute myocardial infarction: results of the Cooperative New Scandinavian Enalapril Survival Study II (CONSENSUS II). N Engl J Med. 1992;327:678-84.

23. Packer M, McMurray JJV. Importance of endogenous compensatory vasoactive peptides in broadening the effects of inhibitors of the renin-angiotensin system for the treatment of heart failure. Lancet. 2017;389:1831-40. doi: 10.1016/S01406736(16)30969-2.

24. Mann JF, Schmieder RE, McQueen M, Dyal L, Schumacher H, Pogue J, et al. Renal outcomes with telmisartan, ramipril, or both, in people at high vascular risk (the ONTARGET study): a multicentre, randomised, double-blind, controlled trial. Lancet. 2008;372:547-53

25. Barnett AH, Bain SC, Bouter P, Karlberg B, Madsbad S, Jervell $\mathrm{J}$, et al. Angiotensin-receptor blockade versus convertingenzyme inhibition in type 2 diabetes and nephropathy. N Engl J Med. 2004;351:1952-61.

26. Catala-Lopez F, Macias Saint-Gerons D, Gonzalez-Bermejo D, Rosano GM, Davis BR, Ridao M, et al. Cardiovascular and renal outcomes of renin-angiotensin system blockade in adult patients with diabetes mellitus: a systematic review with network meta-analyses. PLoS Med. 2016;13:e1001971. doi: 10.1371/journal.pmed.1001971.

27. Yusuf S, Diener HC, Sacco RL, Cotton D, Ounpuu S, Lawton WA, et al. Telmisartan to prevent recurrent stroke and 
cardiovascular events. N Engl J Med. 2008;359:1225-37. doi: 10.1056/NEJMoa0804593.

28. Bavishi C, Ahmed M, Trivedi V, Khan AR, Gongora C, Bangalore $\mathrm{S}$, et al. Meta-Analysis of Randomized Trials on the Efficacy and Safety of Angiotensin-Converting Enzyme Inhibitors in Patients >65 Years of Age. Am J Cardiol. 2016;118:1427-36.

29. Law MR, Wald NJ, Morris JK, Jordan RE. Value of low dose combination treatment with blood pressure lowering drugs: analysis of 354 randomised trials. BMJ. 2003;326:1427. DOI:10.1136/bmj.326.7404.1427.

30. Banerji A, Blumenthal KG, Lai KH, Zhou L. Epidemiology of ACE Inhibitor Angioedema Utilizing a Large Electronic Health Record. J Allergy Clin Immunol Pract. 2017;5:744-749. doi: 10.1016/j.jaip.2017.02.018.

31. Regulska K, Stanisz B, Regulski M. The renin-angiotensin system as a target of novel anticancer therapy. Curr Pharm
Des. 2013;19:7103-25.

32. Pasternak B, Svanstrom $H$, Callreus $T$, Melbye $M$, Hviid A. Use of angiotensin receptor blockers and the risk of cancer. Circulation. 2011;123:1729-36. doi: 10.1161/ CIRCULATIONAHA.110.007336.

33. Yoon C, Yang HS, Jeon I, Chang Y, Park SM. Use of angiotensinconverting-enzyme inhibitors or angiotensin-receptor blockers and cancer risk: a meta-analysis of observational studies. CMAJ. 2011;183:E1073-84. doi: 10.1503/cmaj.101497.

34. Shen J, Huang YM, Wang M, Hong XZ, Song XN, Zou X, et al. Renin-angiotensin system blockade for the risk of cancer and death. J Renin Angiotensin Aldosterone Syst. 2016;17. doi: 10.1177/1470320316656679.

35. Cronin-Fenton D. Angiotensin converting enzyme inhibitors and lung cancer. BMJ. 2018;363:k4337. doi: 10.1136/bmj. k4209. 